\title{
A Study on Quantitative Analysis Method for Project Bidding Decision
}

\author{
Zuhua Guo*, Xinling Sun andYong Wei
}

Computer Science and Technology Department, Henan Mechanical and Electrical Engineering College, Xinxiang, Henan, 453002, P. R. China

\begin{abstract}
Bidding decision is a complex issue that refers to unstructured multi-level group decision making and game theory. For analyzing the process of project biding, a mathematical statistics analysis method, based on the quotation level and bidding rate, was proposed. Based on the discussion of the mathematical curve fitting, the method of regression equation calculation based on the significance of linear regression equation, the mathematical model of quotation level and winning rate was constructed. According to the case study, the designed method improved the bidding rate of biding contractor and reduced the blindness of bidding decision. therefore, it was concluded that this method is scientific and effective.
\end{abstract}

Keywords: Curve fitting method, linear regression significance, project bidding, quantitative analysis method, quotation decision mathematical model.

\section{INTRODUCTION}

Bidding decision is very important for any bidding unit, as unwise bidding decision results in a tremendous waste of resources, poor business management, which in turn affect the achievement of the strategic objectives of the bidding unit. A rational and competitive quotation level is the core of a successful project. Currently, many cities have actively promoted project bidding by taking assistance of computer and network. Quotation decision mathematical method for project bidding is an important content for research which is designed [1] to achieve $t$ online bidding system and the support systems for evaluating the success of the bidding unit [2].

\section{RELATED RESEARCHES AND OUR WORKING}

Project bidding quotation is a process that refers to the analysis of the technology, construction programs, bidding unit requirements, the enterprise management level, construction level, project market and competitive process of project quotation. According to the analysis, it can help in making the project quotation decision within limited time. The bidder solves the problem of increasing the winning rate of biddings in strong competition to gain the highest profit in the project biddings.

Project biding is a complex issue that refers to unstructured multi-level group decision making and game theory. Currently, researches on project bidding quotation strategy $[3,4]$ have made considerable achievements, and constructed a mathematical model of project biddings. Some of them are qualitative researches, some are quantitative analyses, such as unbalanced bidding $[5,6]$, project bidding decisions based

*Address correspondence to this author at the Computer Science and Technology Department ,Henan Mechanical and Electrical Engineering College, Xinxiang, Henan, 453002,P. R. China; Tel: 13525023658 ; Fax:03733691001; E-mail: 3374035@qq.com on fuzzy logic [7], multiple criteria optimization [8], and competition analysis bidding $[9,10]$. But many of them are too complex to be implemented in computer aided project bidding system. Based on the basic principles and methods of mathematical statistics, this paper proposed a mathematical statistics analysis method of the quotation level and winning rate decisions. This paper used actual cases to verify the usefulness of this method that is simple, scientific and effective to design and develop computer aided project bidding system.

This paper, according to the collected information and data of bidding, calculated the quotation level and winning rate of biddings by mathematical statistics method, drew scatter diagram of quotation and winning rate, and analyzed the linear regression equation of the quotation level and winning rate by mathematical curve fitting method to provide scientific, effective data and information for quantitative decision of project bidding.

\section{MATHEMATICAL MODELS AND CALCULATION METHOD}

\subsection{Construction of Model}

This method assumes that the all previous quotations (1n) $A$ of bidding unit $j$ is $\left(A_{1 j}, A_{2 j}, \ldots, A_{i j}, \ldots, A_{n j}\right)$.

1. Calculation for the standard quotation ratio $N_{i j}$ of all previous quotations of bidding unit $\boldsymbol{j}$. How to calculate the $N_{i j}$ value is shown in formula (1).

$N_{i j}=B_{i j} / A_{i j}$

$N_{i j}$ is the value of the $i$ th standard quotation price ratio of bidding unit $j, A_{i j}$ is the average value of the $i$ th standard quotation price of the bidding unit $j$, and $B_{i j}$ is the $i$ th standard quotation price of the bidding unit $j$. 
2. Calculation for the average value of all previous standard quotation ratios $\boldsymbol{N}_{\boldsymbol{i} j}$ of bidding unit $\boldsymbol{j}$. $N_{i j}$ is also called as the average quotation price ratio. If the bidding unit $j$ has made $n$ times biddings, the calculation of the average value of all previous standard quotation ratios is shown in formula (2).

$\overline{N_{j}}=\sum_{i=1}^{n} N_{i j} / n$

$\overline{N_{j}}$ reflects the quotation level of all $\mathrm{n}$ times biddings of bidding unit $\mathrm{j}$. If $\overline{N_{j}}$ is less than 1 , it shows that the quotation level is lower, and if $\overline{N_{j}}$ equals to 1 , it shows that the quotation level is medium. However, if $\overline{N_{j}}$ is larger than 1 , it shows that the quotation level is higher.

3. Calculation of bidding rate and drawing of scatter diagram. If the number of winning bidding of all $n$ times is $V_{j,}$, the bidding rate is calculated as shown in the formula (3).

$P_{j}=V_{j} / n$

Assuming that the point $J\left(\overline{N_{j}}, P_{j}\right)$, under the rectangular Cartesian coordinate system considers $\bar{N}, P$ as $x, y$ coordinates respectively, with mathematical statistics value of quotation level and bidding rate of the bidding unit $\mathrm{j}$, mathematical statistics value of quotation level $\overline{\left(N_{1}\right.}, \overline{N_{2}} \ldots \overline{N_{i}}$, $\left.\ldots \overline{N_{m}}\right)$ and bidding rate $\left(P_{1}, P_{2}, \ldots P_{i}, \ldots P_{m}\right)$ of all $\mathrm{m}$ bidding units can be calculated. Drawing the points $\overline{\left(N_{1}\right.}$ ,$\left.P_{1}\right),\left(\overline{N_{2}}, P_{2}\right), \ldots\left(\overline{N_{i}}, P_{i}\right), \ldots\left(\overline{N_{m}}, P_{m}\right)$ under the same rectangular Cartesian coordinate system, the mathematical statistics scatter diagram of quotation level and bidding rate was obtained as shown in Fig. (1).

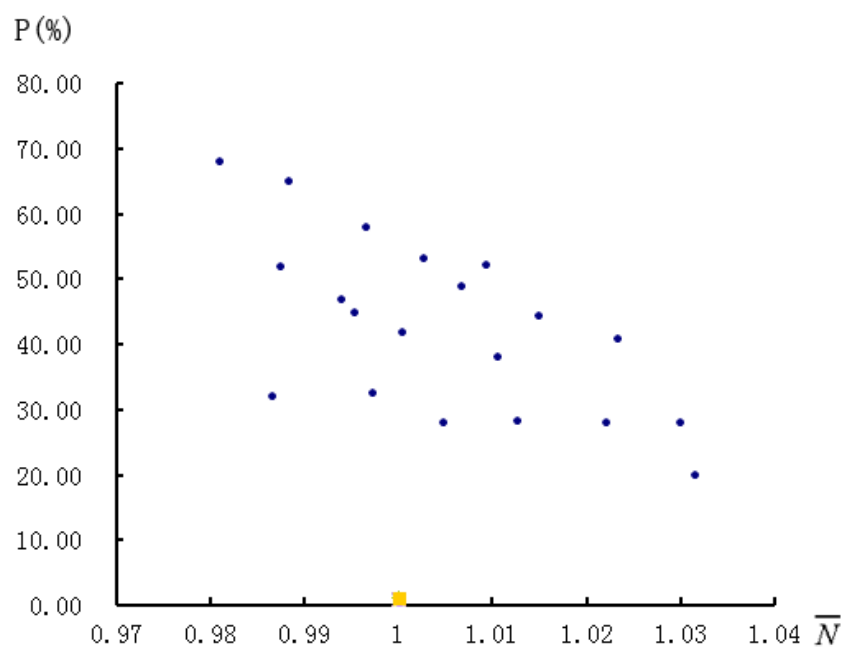

Fig. (1). The scatter diagram of the average quotation level $\overline{\mathrm{N}}$ and bidding rate $P$.

\subsection{Mathematical Curve Fitting of Scatter Diagram of ( $\left.\overline{N_{i}}, \quad P_{i}\right)$ Value}

In Fig. (1), mathematical curve fitting method was used to obtain the experience curve of the average quotation level $\overline{\mathrm{N}}$ and the bidding rate $\mathrm{P}$, and the experience formula is shown in formula (4).
$P=f(\bar{N})$

Using the experience curve or empirical formulas, not only the corresponding bidding rate of different quotation levels can be obtained, but this can also accord with the bidding rate to determine the corresponding quotation level.

If sets $x=\bar{N}$ and $y=P$, according to the Fig. (1), it represents a nonlinear relationship between the quotation level $\mathrm{x}$ and the bidding rate $y$. Mathematical curve fitting method is show in formula(5).

$f(y)=a+b g(x)$

If sets $X=g(x)$, and $Y=f(x)$, according to the transformation of formula (5), linear regression equation was obtained as shown in formula (6), and the nonlinear relationship was converted into a linear relationship.

$Y=a+b X$

When $i=1 \sim m$, formula (6) can obtain linear regression equation by calculating $\left(X_{i}, Y_{i}\right)$ with $\left(x_{i}, y_{i}\right)$ and estimating regression coefficient $a$ and $b$ with the least square method. The detailed solution steps are as follows.

Step 1: A scatter diagram of $\left(x_{i}, y_{i}\right)$ is drawn as shown in Fig. (1).

Step 2: Based on past experience and Fig. (1) distribution, a nonlinear regression mathematical model is set up as shown in formula (5).

Step 3: the fitting curve is linearized by calculating $\left(X_{i}\right.$ , $Y_{i}$ ) with $i=1 \sim m$ as shown in formula (6).

Step 4: the value of $Y$ is set as shown in formula (7), and the value of formula (6) is estimated with formula (7).The difference of them is expressed as shown in formula (8).

$Y_{i}^{n}=\hat{a}+\hat{b} X_{i}$

$\varphi(\hat{a}, \hat{b})=\sum_{i=1}^{m}\left[Y_{i}-\left(\hat{a}+\hat{b} x_{i}\right)\right]$

Step 5: To select the minimum value of $\hat{a}+\hat{b}$, the value of $\varphi(\hat{a}, \hat{b})$ is made to reach the minimum. Following this, partial derivatives $\frac{\partial \varphi}{\partial \hat{a}}, \frac{\partial \varphi}{\partial \hat{b}}$ of $\varphi$ are calculated under $\hat{a}+$ $\hat{b}$, and are made equal to zero as shown in formula (9).

$\left\{\begin{array}{l}\frac{\partial \varphi}{\partial \hat{a}}=-2 \sum_{i=1}^{m}\left[Y_{i}-\left(\hat{a}+\hat{b} x_{i}\right)\right] \\ \frac{\partial \varphi}{\partial \hat{b}}=-2 \sum_{i=1}^{m}\left[Y_{i}-\left(\hat{a}-\hat{b} x_{i}\right)\right]\end{array}\right.$ (10).

Step 6: The equations are solved as shown in formula

$\left\{\begin{array}{c}m \hat{a}+m \bar{X} \hat{b}=m \bar{Y} \\ m \bar{X} \hat{a}+\hat{b} \sum_{i=1}^{m} X_{i}^{2}=\sum_{i=1}^{m} X_{i} Y_{i}\end{array}\right.$

It can obtain formula (11) from formula (10).

$\left\{\begin{array}{l}\bar{X}=\frac{1}{m} \sum_{i=1}^{m} X_{i} \\ \bar{Y}=\frac{1}{m} \sum_{i=1}^{m} Y_{i}\end{array}\right.$ 
Because $x_{i}$ is not the same as the value of the coefficient determinant is $\left|\begin{array}{cc}m & m \bar{X} \\ m \bar{X} & \sum_{i=1}^{m} X_{i}^{2}\end{array}\right|=m\left(\sum_{i=1}^{m} X_{i}^{2}-m \bar{X}_{i}^{2}\right) \neq 0$ calculated by formula (10), and the equation (10) has only one set of solution as shown in formula (12).

$\left\{\begin{array}{c}\hat{a}=\bar{Y}-\hat{b} \bar{X} \\ \hat{b}=\frac{\sum_{i=1}^{m} X_{i} Y_{i}-m \overline{X Y}}{\sum_{i=1}^{m} X_{i}{ }^{2}-m \bar{X}_{i}{ }^{2}}\end{array}\right.$

Step 7: After obtaining the value of $\hat{a}$ and $\hat{b}$ based on formula (12), the linear regression equation is shown in formula (7) can be set.

\subsection{Calculation of Linear Regression Equation and Cor- related Coefficient}

After constructing mathematical model of the quotation level and the bidding rate, the relationship between $x$ and $y$ can be found. However, there is a need to calculate the regression equation and correlation coefficient $R$ of $\left(X_{i}, Y_{i}\right)$ to verify whether the linear regression curve can exactly reflect the relationship between the quotation level and the bidding rate and its close degree.

Assuming that the number of the bidding units is $\mathrm{m}$ and the statistical value is $\left(x_{i}, y_{i}\right)$ then the linear arithmetic mean $\bar{X}, \bar{Y}$, can be calculated according to the formula (11), and the process of calculating correlation coefficient $\mathrm{R}$ is shown in formula as follows.

Assuming that the $L_{X X}, L_{Y Y}, L_{X Y}$ represent formulae (12), (13) and (14) respectively.

$L_{X X}=\sum_{i=1}^{m}\left(X_{i}-\bar{X}\right)^{2}=\sum_{i=1}^{m} X_{i}{ }^{2}-m X^{2}$
$L_{Y Y}=\sum_{i=1}^{m}\left(Y_{i}-\bar{Y}\right)^{2}=\sum_{i=1}^{m} Y_{i}^{2}-m Y^{2}$
$L_{X Y}=\sum_{i=1}^{m}\left(X_{i}-\bar{X}\right)\left(Y_{i}-\bar{Y}\right)=\sum_{i=1}^{m} X_{i} Y_{i}-m \overline{X Y}$

The calculation of correlation coefficient $R$ is shown in formula (16).

$\mathrm{R}=\frac{\sum_{i=1}^{m}\left(X_{i}-\bar{X}\right)\left(Y_{i}-\bar{Y}\right)}{\sqrt{\sum_{i=1}^{m}\left(X_{i}-\bar{X}\right)^{2} \sum_{i=1}^{m}\left(Y_{i}-\bar{Y}\right)^{2}}}=\frac{L_{X Y}}{\sqrt{L_{X X L_{Y Y}}}}$

$R$ reflects the close degree of relationship between the regression equation and $\left(X_{i}, Y_{i}\right)$, and the conclusion is as follows:

(1) When $R=0\left(L_{X Y}=0\right)$, it can get $\hat{b}=L_{X Y} / L_{X X}$ and $\hat{b}=0$ by formula (12), (13) and (15), and the result shows that the change in $Y$ has nothing to do with $X$. therefore, there is no the linear relationship exists between $X$ and $Y$.

(2) When $0<|R|<1$, it shows that there exists a certain linear relationship between $X$ and $Y$. The smaller the absolute value of $R$, the smaller the correlation is, but on the contrary, the correlation is higher.

(3) When $|R|=1$, there is a complete linear relationship between $X$ and $Y$. If $R=1$, the relationship is perfect positive correlation, and if $R=-1$, the relationship is perfect negative correlation.
The above analysis showed that the absolute value of correlation coefficient $R$ was more close to 1, and the correlation between $X$ and $Y$ was more close. It can be said that the nonlinear mathematical model of the quotation level $x$ and bidding rate $y$ is more in accordance with the actual situation of project bidding.

\subsection{Significance Test}

The above calculation shows that the higher the absolute value of correlation coefficient $R$, the better is the regression, and the more significant the linear relationship will be., Contrarily the worst the regression is, and the less significant the linear relationship will be . There are three methods to test the significance of linear regression.

(1) F-test

F-test is shown in formula (17). It can verify the linear correlation between $\mathrm{X}$ and $\mathrm{Y}$ by considering $\mathrm{F}$ distribution table.

$\mathrm{F}=(n-2) \frac{R^{2}}{1-R^{2}}: F(1, n-2)$

(2) T-test

T-test is shown in formula (18), the value of $\mathrm{s}$ is shown in formula (19). It can verify the linear correlation between $\mathrm{X}$ and $\mathrm{Y}$ by considering $\mathrm{t}$ distribution table.

$\mathrm{t}=\frac{\hat{b}}{s} \sqrt{L_{X X}}: t(n-2)$

$\mathrm{s}=\sqrt{\frac{L_{X Y} L_{Y Y}-L_{X Y}{ }^{2}}{(n-2) L_{X X}}}, \quad \hat{b}=L_{X Y} / L_{X X}$

(3) R-test

Because $(n-2) \frac{K^{-}}{1 R^{2}}>F_{1-\alpha}(1, n-2)$, the critical value of $\mathrm{R}$ can be solved by formula (20). It can verify the linear correlation between $X$ and $Y$ by considering $\mathrm{R}$ distribution table.

$|R|=\sqrt{\frac{1}{\frac{n-2}{F_{1-\alpha}(1, n-2)+1}}}$

The above described three kinds of testing methods are actually completely equivalent. When $\alpha$ equals to 0.05 , it is considered as a significant test level and the confidence is $95 \%$. The results of tests were, $|t|=t_{0.975}(n-2), \mathrm{F}=$ $F_{0.95}(n-2)$ and $|R|>R_{0.05}$, therefore, the regression is significant. When $\alpha$ to equals 0.001 , it is considered as a significant test level and the confidence is $99.9 \%$. The results of tests were $|t|=t_{0.9995}(n-2), \quad \mathrm{F}=F_{0.999}(n-2)$, $|R|>R_{0.001}$, therefore, the regression is extremely significant.

As F-test is simpler, it is often used to deal with practical problems.

\section{EXPERIMENT RESULT AND DISCUSSION}

Based on the above research and discussion, in order to verify the validity of the above methods, the project application and verification results, the quotation level and winning rate data of 10 bidding units were taken into consideration with more than 100 times project bidding, which was pro- 
Table 1. The statistical results of the quotation level and winning rate data of $\mathbf{1 0}$ bidding units.

\begin{tabular}{|c|c|c|c|c|c|}
\hline Bidder(i) & $\mathbf{1}$ & $\mathbf{2}$ & $\mathbf{3}$ & $\mathbf{4}$ & 0.992 \\
\hline Quotation(x) & 0.979 & 0.982 & 0.985 & $\mathbf{0 . 1 2 2}$ & 0.997 \\
\hline Bidding Rate(y) & 0.142 & 0.141 & 0.118 & 9 & 1.088 \\
\hline Bidder(i) & 6 & 7 & 8 & 1.013 & 0.062 \\
\hline Quotation(x) & 1.003 & 1.006 & 0.088 & 0.064 \\
\hline Bidding Rate(y) & 0.091 & 0.086 & & 0.06 \\
\hline
\end{tabular}

Table 2. The results of related parameters.

\begin{tabular}{|c|c|c|c|c|c|c|}
\hline$x_{i}$ & $X_{i}=\ln x_{i}$ & $X_{i}^{2}$ & $y_{i}$ & $Y_{i}=\ln y_{i}$ & $Y_{i}^{2}$ & $X_{i} Y_{i}$ \\
\hline 0.979 & -0.02122 & 0.00045 & 0.142 & -1.95193 & 3.81002 & 0.04143 \\
\hline 0.982 & -0.01816 & 0.00033 & 0.141 & -1.95900 & 3.83766 & 0.03558 \\
\hline 0.985 & -0.01511 & 0.00023 & 0.118 & -2.13707 & 4.56707 & 0.03230 \\
\hline 0.992 & -0.00803 & 0.00006 & 0.122 & -2.10373 & 4.42570 & 0.01690 \\
\hline 0.997 & -0.00300 & 0.00001 & 0.088 & -2.43042 & 5.90693 & 0.00730 \\
\hline 1.003 & 0.00300 & 0.00001 & 0.091 & -2.39690 & 5.74511 & -0.00718 \\
\hline 1.006 & 0.00598 & 0.00004 & 0.086 & -2.45341 & 6.01921 & -0.01468 \\
\hline 1.013 & 0.01292 & 0.00017 & 0.088 & -2.43042 & 5.90693 & -0.03139 \\
\hline 1.019 & 0.01882 & 0.00035 & 0.062 & -2.78062 & 7.73185 & -0.05234 \\
\hline 1.028 & 0.02762 & 0.00076 & 0.064 & -2.74887 & 7.55630 & -0.07591 \\
\hline$\sum$ & 0.00279 & 0.00241 & 1.00200 & -23.39236 & 55.50679 & -0.04799 \\
\hline
\end{tabular}

vided by the Henan Xinxiang Public Resources Trading \& Service Center as examples to analyze. At the same time, a computer aided construction project bidding decision system was developed, which laid the foundation for the practice of the method. The statistical results are shown in Table $\mathbf{1 .}$

(1) According to the data of Table 1, the mathematical statistics scatter diagram of quotation level $\mathrm{x}$ and bidding rate y was dawn as shown in Fig. (2).

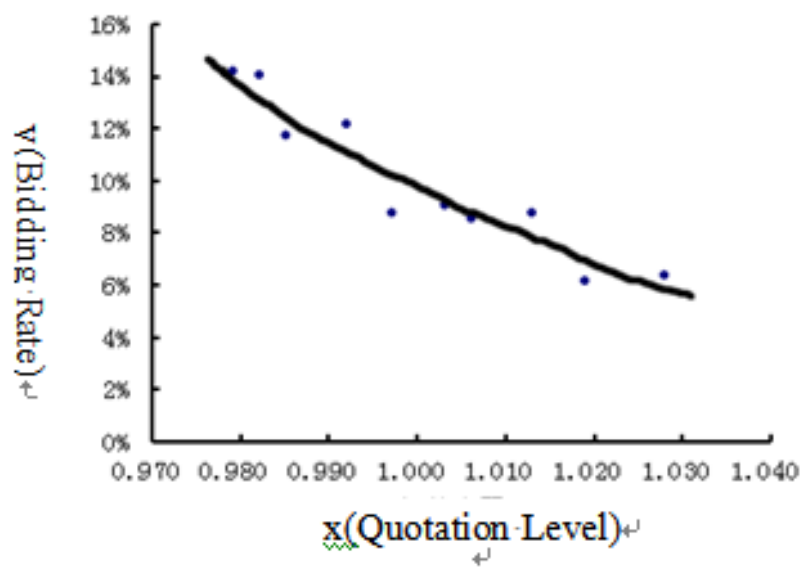

Fig. (2). The scatter diagram of $\left(\overline{N_{i}}, P_{i}\right)$ value.

(2) Based on the characteristics of Fig. (2), the function of quotation level and bidding rate was used to draw the curve as shown in formula (21).
$\mathrm{y}=\mathrm{Ax} \mathrm{x}^{-\mathrm{B}}$

(3) Linearizing the fitting curve, if $y=\ln A-B \ln x$, set $X=\ln x, Y=\ln y, a=\ln A, b=-B$, then $Y=a+b X$ was obtained .

(4) The estimated parameters $\hat{a}, \hat{b}$ were calculated, and the results are shown in Table 2.

(5) Based on the results of Table 2, following data was obtained, $\bar{X}=\frac{1}{10} \sum_{i=1}^{10} X_{i}=0.000279$ and $\overline{\mathrm{Y}}=\frac{1}{10} \sum_{\mathrm{i}=1}^{10} \mathrm{Y}_{\mathrm{i}}=$ -2.33924 . By solving the linear regression equation $Y=a+b X$, the estimated parameters $\hat{a} \hat{b}$ were obtained by formula (12), along with $Y_{i}^{*}=-2.33443-17.2004 x_{j}^{*}$. By putting $\hat{a} \quad \hat{b}$ into formula $\hat{\mathrm{b}}=\frac{\sum_{\mathrm{i}=1}^{\mathrm{m}} \mathrm{X}_{\mathrm{i}} \mathrm{Y}_{\mathrm{i}}-\mathrm{m} \overline{\mathrm{X}} \overline{\mathrm{Y}}}{\sum_{\mathrm{i}=1}^{\mathrm{m}} \mathrm{X}_{\mathrm{i}}{ }^{2}-\mathrm{m} \overline{\mathrm{X}}_{\mathrm{i}}^{2}}=\frac{-0.04799-10 \times 0.000279 \times(-2.33924)}{0.00241-10 \times(0.00241)^{2}}=-17.2007$, $\hat{a}=\bar{Y}-\hat{b} \bar{X}=-2.33924-17.2004 \times 0.000279=$ $-2.33443$

(6) The correlation coefficient $\mathrm{R}$ was calculated by formula (13), (14), (15), (16). By using the Table 2 , $L_{x x}=$ $0.04145, L_{Y Y}=0.00241, L_{X Y}=0.786533$ and $R=-0.95212$ were obtained respectively. Because the value of $|R|$ was close to 1 the correlation between $X$ and $Y$ was also closer.

(7) Analyzing the regression significance, F-test is simpler, and it is often used to deal with practical problems. $\mathrm{F}=$ 77.58443 was obtained by formula (17). When the critical value $\alpha$ was equal to 0.05 , the value of $F$ was set as 
$\mathrm{F}_{1-\alpha}(1,10-2)=\frac{1}{F_{0.05}(8,1)}=0.0042$ by considering $\mathrm{F}$ distribution table.

Because 77.58443>0.0042, which suggested that the regression analysis is significant. When the critical value $\alpha$ was equal to 0.005 , the value of $F$ was set as $F_{1-\alpha}(1,10-$ $2)=\frac{1}{F_{0.005}(8,1)}=0.00004$ by considering $F$ distribution table. Because $77.58443>0.00004$, it can be said that the regression analysis is significant.

(8)The linear equation was transformed into nonlinear regression equation. When $\mathrm{A}=e^{\hat{a}}=e^{-2.33443}=0.09686$, $\mathrm{B}=-\hat{\mathrm{b}}=-17.2004$, then the value of $\mathrm{Y}$ was $\mathrm{y}=$ $0.09686 x^{-17.2004}$ obtained by putting $A$ and $B$ into formula (21).

By the obtained nonlinear curve, the fitting curve was drawn as shown in Fig. (2).

\section{CONCLUSION}

At present, the reasonable low price method and the comprehensive evaluation method are often used to evaluate bidding in China, and the quotation is sixty or seventy percent of the total value that is calculated by the reasonable low price method and the comprehensive evaluation method. As a result, the reasonable quotation is the key to win bidding. According to the calculation results, the method proposed in the study is an objective, effective and scientific quantitative analysis method for project bidding decision. Because the method is based on previous quotation and bidding strategy, therefore for using the method to formulate quotation decision strategy and offer quotation quantitative analysis, attention should be paid to the following aspects: (1) when determining final quotation, the bidding unit should strengthen the understanding of macro policy, strengthen the market analysis and research, and should fully consider the status strategic planning.(2) It is necessary to collect enough statistical data, and carefully analyze all previous similar project bidding information of other competitive bidding units.(3) It is also important to consider some variables, such as project material price growth, inflation and technological progress, market supply and demand, to keep the quantitative analysis results comparable and objective.(4) Quotation should be close to the owner or close to the optimal price for the best bidding unit. The reasonable low quotation price should be calculated on the basis of fully estimating and analyzing the base price of the bidding unit. Moreover, for comprehensive quotation, the evaluation method should comprehensively consider many influence factors in quotation, such as owner pre-bidding unit estimate, other bidders' quotation, the weight of each evaluation index, etc.

\section{CONFLICT OF INTEREST}

The authors confirm that this article content has no conflict of interest.

\section{ACKNOWLEDGEMENTS}

This work was supported in part by The Natural Science Research Project of Henan Province Education Department (14A520045, 13A520221).

\section{ABOUT THE AUTHORS}

First Author Guo Zuhua, Associate Professor of Henan Mechanical and Electrical Engineering College, M.S. The author's major is Software Engineering. 4 papers received by EI been published.

Second Author Sun Xinling, University lecturer of Henan Mechanical and Electrical Engineering College, M.S. The author's major is Computer Graphics and Software Engineering.

Third Author Wei Yong, University lecturer of Henan Mechanical and Electrical Engineering College.

\section{REFERENCES}

[1] Y. Q. Shen, "Design and Development of Online Bidding System", M.S. thesis, University of Electronic Science and Technology of China, Chengdu, China, 1999.

[2] L. He, "Study and Design of Network Bidding System of Government Purchasing", M.S. thesis, Chongqing university, Chongqing, China, 2004.

[3] X. R. Xia, "Study on Bidding Price Decision of Construction Project", M.S. thesis, Beijing Jiaotong University, Beijing, China, 2007

[4] X. P. Liu, "Discussing on Engineer Project Pricing Decision Models", Shanxi Architecture, vol. 34, no. 3, pp. 273-274, 2008.

[5] X. C. Liang, "The Legitimacy of Unbalanced Bidding Application", Journal of Engineering Management, vol. 27, no. 4, pp. 31$35,2013$.

[6] X. L. Zhao, L. Gao and K. He, "Study on Unbalanced Bidding", Construction Economy, vol. 7, pp. 102-104, 2009.

[7] E. L. Liu, J. Wang and G. Luo, "Project bidding decision on fuzzy logic", China Civil Engineering Journal, vol.36, no. 3, pp. 57-63, 2003.

[8] R E. Steuer, "Multiple Criteria Optimization: Theory Computation and Application", New York: Wiley, 1996.

[9] P. L. Deng and J. X. Yuan, "Strategic Analysis of Competition in Inviting and Taking Bidding", Mathematics in Practice and Theory, vol.41, no. 12, pp. 94-98, 2011.

[10] L. J. P. Hao, "Bid Quote Price Game Model", M.S. thesis, Harbin University of Science and Technology, Harbin, China, 2003.

Received: December 05, $2014 \quad$ Revised: January 20, 2015

(C) Guo et al., Licensee Bentham Open.

This is an open access article licensed under the terms of the Creative Commons Attribution Non-Commercial License (http:/creativecommons.org/licenses/by-nc/4.0/) which permits unrestricted, non-commercial use, distribution and reproduction in any medium, provided the work is properly cited. 